\title{
MIGUEL MIGUEL: O FANTÁSTICO TRADUZIDO PARA O CINEMA
}

\author{
Wellingson Valente dos Reis (UNAMA) \\ José Guilherme de Oliveira Castro (UNAMA) \\ Lucilinda Ribeiro Teixeira (UNAMA)
}

Recebido em 08 fev 2018. Wellingson Valente dos Reis é Doutorando em Aprovado em 08 mai 2018. Comunicação, Linguagens e Cultura pela UNAMA. Bolsista PROSUP/CAPES. Docente do IFPA - Campus Belém, atuando como professor de Literaturas e Língua Espanhola na Graduação em Letras e nos cursos técnicos, atuando principalmente nos seguintes temas: narrativas fantásticas; literatura, ensino e recepção e intersemiótica; autor de capítulos presentes nos livros: Memórias de Belém de antigamente (EDUEPA) e Ensino de espanhol nos institutos federais: Cenário nacional e experiências didáticas (PONTES), além do artigo "Literatura e cinema: tradução intersemiótica na obra Dona Flor e seus dois maridos e sua adaptação cinematográfica" na revista A Palavrada (UFPA); Membro do Grupo Interdisciplinar de Pesquisa em Arte, Cultura e Educação (GIPACE/IFPA) e do Grupo Interfaces do Texto Amazônico (GITA/UNAMA). Lattes: http://lattes.cnpq.br/9565321075411405. E-mail: wellingsonreis@uol.com.br

José Guilherme de Oliveira Castro é Doutor em Letras pela PUC/RS. Professor titular da Universidade da Amazônia (UNAMA), atuando no Programa de Pós-Graduação em Comunicação, Linguagens e 
Cultura (Mestrado e Doutorado) e na graduação em Letras, atuando principalmente nos seguintes temas: narrativa, conto fantástico, sociedade e lirismo; Autor do livro: A aventura mítica de Miguel dos Santos Prazeres (EDUNAMA) e dos artigos "Narrativas míticas na ilha de Marajó: o caso do Cobra Norato ou Tupinambá" revista Patrimônio e Memória (UNESP) e "Vozes que contam: narrativas orais de imigrantes de Paragominas - PA" Revista Boitatá (UEL); Líder do Grupo Interfaces do Texto Amazônico (GITA/UNAMA). Lattes: http://lattes.cnpq.br/4564267097302078. E-mail: zevone@superig.com.br

Lucilinda Ribeiro Teixeira é Doutora em Comunicação e Semiótica pela PUC/SP. É professora titular da Universidade da Amazônia (UNAMA), atuando no Programa de Pós-Graduação em Comunicação, Linguagens e Cultura (Mestrado e Doutorado) e na graduação em Letras, atuando principalmente nos seguintes temas: Semiótica, Literatura e criação, Criação, transformação e apropriação; Autora dos livros: Ecos da Memória: Machado de Assis em Haroldo Maranhão (Annablume) e Estudos Intersemióticos Linguagens: Estudos Interdisciplinares e Multiculturais (EDUNAMA) e do artigo "A crítica literária e a polêmica jornalística: as contribuições de Aluísio Azevedo e Machado de Assis" Revista USP (USP); Líder do Grupo Interfaces do Texto Amazônico (GITA/UNAMA). Lattes: http://lattes.cnpq.br/4264593536351653. E-mail: lucilindateixeira@gmail.com

Resumo: Este estudo tem como objetivo observar por meio da intermidialidade, intersemiótica e intertextualidade, como se deu a tradução da obra Miguel Miguel de Haroldo Maranhão para o cinema e quais elementos foram usados para a criação do filme homônimo de Roger Elarrat. Como o foco da obra Miguel Miguel de Haroldo Maranhão é o fantástico, optou-se por analisar essa tradução pelo viés da 
construção do fantástico em cada uma das obras. Este estudo de tradução foi realizado por meio de leituras bibliográficas e teve como referências os estudos de tradução, adaptação, cinema e literatura de Tavares (1996) e Xavier (2003); para basear essa tradução entre artes diferentes buscou-se o apoio nas teorias de Intersemiótica de Plaza (2003), de intermidialidade de Clüver (2006) e da liberdade de inter-relações entre as artes defendida por Rancière (2012). O estudo também focou na contemporaneidade do escritor Haroldo Maranhão, que possibilitou uma maior liberdade da produção do filme. Além dos teóricos do fantástico que embasaram a análise, entre eles Todorov (2014), Ceserani (2006) e Chiampi (2015). Palavras-chave: Tradução; Fantástico; Miguel Miguel.

Abstract: This study aims to observe through intermidiality; Intersemiotic and intertextuality, as was the translation of Haroldo Maranhão's Miguel Miguel for television, which elements were used to create the homonymous mini-series by Roger Elarrat. As the focus of the work Miguel Miguel by Haroldo Maranhão is fantastic, it was decided to analyze this translation for the bias of the construction of the fantastic in each of the works. This study of translation was made through bibliographical readings and had as references the studies of translation, adaptation, cinema and literature of Tavares (1996) and Xavier (2003); To base this translation among different arts, we sought support in the theories Intersemiotica of Plaza (2003), intermidiality of Clüver (2006) and the freedom of inter-relations between the arts defended by Rancière (2012). The study also focused on the contemporaneousness of the writer Haroldo Maranhão, which allowed a greater freedom of production of the series. Besides the fantastic theorists who supported the analysis, among them Todorov (2014), Ceserani (2006) and Chiampi (2015).

Keywords: Translation; Fantastic; Miguel Miguel. 


\section{O ROTEIRO: UMA INTRODUÇÃO}

O cinema e a literatura são duas artes que a todo o momento se relacionam. Afinal, é muito comum termos obras literárias sendo adaptadas para o cinema. Esta relação sempre foi muito polêmica, e se estabeleceu quando o cinema percebeu que tinha um grande potencial para contar histórias. Tavares (2006) diz que o cinema ajudou a literatura em sua experimentação estética, uma vez que, quando o cinema se afirmou como o grande meio para contar histórias, tirou essa obrigação da literatura:

Quando a fotografia aparece, a pintura sente-se finalmente liberta para seu grande voo formal. E enquanto o cinema surge, a literatura sente que a sua hora chegou. Não mais narrar simplesmente. A grande máquina narrativa acabara de nascer. Agora era o instante mesmo da criação, dos desvios, do gozo provocado pelas palavras que ultrapassam o contar, tornando-se, elas mesmas, potenciais poemas. Deixam de ser habituais, e ao ser retiradas desta obrigação do contar, tornam-se plásticas, imaginéticas. (TAVARES, 2006, p.7)

No pensamento de Tavares (2006), o cinema e literatura são artes correlatas, assim como a fotografia e a pintura que, cada uma com as suas técnicas, possuem uma relação que está na essência delas. Podemos dizer que a arte cinematográfica e televisiva tem como segunda natureza a vertente narrativa. Traz, a princípio, embutido em seu processo, a narração, o ato de contar histórias, processo extremamente ligado à literatura. Mesmo que seja no sentido oposto, numa lógica contrária, posto que aquilo que na literatura é visado como efeito (a imagem), no cinema e na televisão é dado como matéria narrativa. 
Essa aproximação foi possível, segundo Ávila (1990) em seu artigo "mídia do século 20 transforma o fazer poético", no jornal Folha de São Paulo, devido à "modernidade", que acabou colaborando para a expansão dos novos meios de comunicação e transmissão, como o cinema e acabaram por transformar a literatura e o fazer poético.

Apesar da aproximação entre as artes, algumas marcas enunciativas são bastante diferentes. É o caso do tempo nas duas expressões artísticas. Enquanto a narrativa literária tem seu tempo marcado no passado, com presença de vários momentos de flashbacks, a narrativa cinematográfica foca seu tempo no presente, tendo o cuidado de usar o recurso de voltar ao passado com bastante moderação para que a narrativa não se torne cansativa.

Este artigo, portanto, irá investigar a adaptação/tradução da obra Miguel Miguel de Haroldo Maranhão (1993) para o cinema, feita pelo diretor Roger Elarrat (2010), tendo em vista a reconstrução do fantástico pela intermidialidade e a recontextualização sofrida pelo discurso narrativo da obra de Haroldo Maranhão nesta nova roupagem.

\section{A PRÉ-PRODUÇÃO: DISCUSSÕES SOBRE ADAPTAÇÃO/TRADUÇÃO}

Em pleno século XXI, vivemos a era dos avanços tecnológicos e, dentro destes avanços, estão inseridas as artes; é claro que cada arte possui processos formais e enunciativos, com características e técnicas próprias, porém dentro deste avanço tecnológico cada vez mais as fronteiras entre as artes atenuam-se.

Assim, filme, fotografia, desenho, caligrafia e poema vêm misturar seus poderes e intercambiar 
suas singularidades. Já não é simplesmente a literatura que constrói seu tornar-se-pintura imaginário, nem a fotografia que evoca a metamorfose literária do banal. São os regimes de expressão que se entrecruzam e criam combinações singulares de trocas, fusões e afastamentos. (RANCIÈRE, 2012, p.119)

Dessa forma, "o processo de hibridização nos permite fazer os meios dialogarem" (PLAZA, 2003, p.65). A hibridização de dois ou mais meios possibilita o surgimento de novas formas de interação entre as artes, e não é possível mais ignorar que a criação, hoje, seja a soma de interações práticas interdisciplinares como forma de tradução.

Falar em tradução de livros sempre foi muito comum, a tradução de um idioma para outro é muito comum no meio literário, porém agora estamos falando da tradução de livros para outros meios, como filmes, séries, peças e jogos. Além disso, a cada minuto, textos novos são lançados na rede, e uma nova combinação forma-se ao redor do texto, do som e da imagem, dispostos em contextos distintos e em novas e impensadas relações. De acordo com Veneroso:

É clara a tendência em direção à combinação entre as diferentes linguagens. Nas artes plásticas os limites entre desenho, pintura, gravura e escultura já não são mais estáveis. O surgimento de novas mídias tem colaborado para a destruição de limites até mesmo entre as artes plásticas, música, teatro, literatura, cinema, vídeo, fotografia, etc. Uma análise da arte atual, tem necessariamente, que levar em consideração essa interação entre as linguagens. (2006, p.47) 
Partindo desse entrecruzamento das linguagens, Claus Clüver (2006) propõe a reflexão de três conceitos para pensar essa relação, a saber: intertexto, interartes e intermídia. Ao refletir sobre a relação entre os meios pelo viés da intertextualidade, leva-se em consideração que uma obra de arte é compreendida como uma estrutura de signos que é lida. Por isso, a obra, independentemente de seu signo, é entendida como "texto". Clüver ressalta que:

Um balé, um soneto, um desenho, uma sonata, um filme e uma catedral, todos figuram como "textos" que se "leem"; o mesmo se pode dizer de selos postais, uma procissão litúrgica e uma propaganda na televisão. Contra essa ampliação do conceito de "texto" na perspectiva semiótica foi levantada a objeção de que ela conduziria a uma supervalorização do modelo linguístico, especialmente em associação ao ato de "ler" (em sentido expressamente metafórico). Por experiência própria, penso que isso é uma questão de hábito e que a palavra "texto" na aplicação intertextual, rapidamente se torna uma palavra neutra. $(2006$, p.15)

Partindo dessa ideia de intertextualidade, Ismail Xavier, em seu artigo "Do texto ao filme: a trama, a cena e a construção do olhar", publicado no livro Literatura, Cinema e Televisão, em 2003, fala que, quando se trata de uma adaptação literária para o cinema, normalmente a discussão se concentra na interpretação que o cineasta faz do livro. Analisa-se o filme para ver o quanto a interpretação do cineasta se aproxima ou se afasta do texto original. Obviamente, esse julgamento será extremamente tendencioso, e abarcará apenas a visão do crítico que o faz. O certo seria perceber os "deslocamentos inevitáveis que ocorrem na cultura, mesmo quando se quer repetir, 
e passou-se a privilegiar a ideia do 'diálogo' para pensar a criação das obras, adaptadas ou não" (XAVIER, 2003, p.61)

Concordando com Johnson (1987), Xavier diz que o filme e o livro possuem em comum a forma narrativa, pois, em ambos os casos, quem narra, escolhe o que mostra, quando mostra e como mostra. O fato de a narração ser um terreno comum entre o livro e o filme permite que ela seja estudada usando categorias comuns na descrição dos elementos que caracterizam a obra, pois a narrativa pode ser estudada sem considerar as particularidades do seu meio de transmissão. Pode-se estudar o tempo, o espaço, os tipos de ação, as personagens e os procedimentos de narração sem especificar se o meio de comunicação é feito por palavras ou por imagens. Diante de qualquer discurso narrativo, seja ele do livro ou do filme, temos a fábula e a trama, sendo a fábula, a história com seus personagens e acontecimentos; já a trama, o modo como esses elementos se dispõem.

Já Clüver (2011) avança no pensamento de Xavier, e entende que a intertextualidade é uma das formas de analisar a tradução/ adaptação. Para ele, além dela é possível pensar a tradução por meio da interartes e por meio da intermidialidade. Não focaremos nos conceitos de interartes, e sim no de intermidialidade, que pode ser entendido como:

um termo relativamente recente para um fenômeno que pode ser encontrado em todas as culturas e épocas, tanto na vida cotidiana como em todas as atividades culturais que chamamos de "arte". Como conceito, "intermidialidade" implica todos os tipos de inter-relação e interação entre mídias. (CLÜVER, 2011, p.9) 
Ainda sobre esse conceito, Moser pontua que a "relação entre as artes, por implicação, comporta sempre, também, questões intermidiáticas, mesmo que não sejam assim explicitadas, considerando-se que toda arte inclui a midialidade". (2006, p.42). Quando se refere à mídia não se deve pensar, portanto, em cinema, rádio, televisão, como é de costume se pensar no Brasil, mas também as outras linguagens, como a literatura, dança, pintura, artes plásticas entre outros. A relação entre as mídias pode acontecer sem que a arte esteja presente. Dessa forma, os estudos de intermidialidade permitem a análise de textos midiáticos com caráter artístico ou não. $\mathrm{A}$ "intermidialidade permite compreender fenômenos complexos de comunicação, que vão da literatura ao cinema, da arte de vanguarda aos programas de tele-realidade." (MÜLLER, 2008, p.52).

Diante disso, compreende-se que o texto midiático se processa no âmbito dos discursos sincréticos, cujo texto "recorre a dois ou mais sistemas de signos e/ou mídias de uma forma tal que os aspectos visuais e/ou musicais, verbais, cinéticos e performativos dos seus signos se tornam inseparáveis e indissociáveis." (CLÜVER, 2006, p.20). Há três tipos de discursos sincréticos: as relações midiáticas ou transposição midiática, multimídia, e a mixmídia.

Transposição midiática ou relação midiática: consiste na interpretação ou tradução de signos verbais por intermédio de signos não verbais. Um texto multimídia forma-se a partir de textos separados e isoladamente coesos, compostos em mídias distintas. Já a definição que se dá à mixmídia é quando ocorre a combinação de textos separados, no entanto, eles não são autossuficientes. São textos que contêm signos complexos dentro de mídias diferentes 
e que perderiam a coerência fora de determinado contexto. A música para o cinema ou para TV, um cenário ou figurino que só exercem uma função dentro de uma encenação, um videoclipe ou até mesmo uma inscrição verbal em textos visuais, como os quadrinhos, são exemplos marcantes de mixmídia, tais sistemas de signos são combinados e não se sustentam sozinhos.

O filme Miguel Miguel, foco de análise deste artigo, em sua feitura, pode ser visto como interação obtida por intermidialidade, em específico a transposição midiática, pois o texto de Haroldo Maranhão se desloca para outro meio, que é o televisivo, podendo ser visto de uma maneira intertextual e intermidiática, mas também está presente o texto mixmídia, através do figurino e do cenário, e o texto multimídia, pela presença da trilha sonora.

A Intermidialidade propicia que se ultrapassem as fronteiras que separam as mídias. É necessário, contudo, que haja um intenso processo de tradução para fazer com que a mensagem migre de uma mídia para outra. Sem modificação é inviável a fusão ou união que a intermidialidade propõe.

Quando um texto é traduzido para outro meio, há de se explorar as substituições que serão feitas, assim como pensar nas possibilidades e limitações que a mídia oferece. A intermidialidade requer tradução. Não podemos esquecer que toda tradução é feita por uma pessoa que antes foi leitor e, por isso, tem sua própria interpretação da obra "os espectadores (leitores) veem, sentem e compreendem alguma coisa à medida que compõem seu próprio poema, como o fazem, à sua maneira, atores ou dramaturgos, diretores, dançarinos ou performers" (RANCIÈRE, 2012, p.18). 


\section{OS DIRETORES: OS QUE NÃO SÃO MIGUEIS}

Haroldo Maranhão é considerado um escritor contemporâneo com habilidades de criar textos ficcionais em variados estilos, uma capacidade que é inerente à sua prosa. O autor possui uma facilidade em criar múltiplas formas para construir histórias com diferentes contextos.

A literatura contemporânea não será necessariamente aquela que representa a atualidade, a não ser por uma inadequação, uma estranheza histórica que a faz perceber as zonas marginais e obscuras do presente, que se afastam de sua lógica. Ser contemporâneo, segundo esse raciocínio, é ser capaz de se orientar no escuro e, a partir daí ter coragem de reconhecer e de se comprometer com um presente com o qual não é possível coincidir. (SCHOLLHAMMER, 2009, p.10)

O autor é contemporâneo não apenas por escrever em um determinado momento histórico, mas sim porque consegue produzir textos que não se acomodam perante a realidade social. Mesmo produzindo obras fantásticas como Miguel Miguel, Maranhão não perde de vista a crítica social, se aproximando do chamado realismo fantástico, que será melhor explicado mais à frente.

Haroldo Maranhão nasceu na cidade de Belém do Pará no dia 7 de agosto de 1927, no entanto, ultrapassa as fronteiras de sua terra e começa uma jornada em vários cantos do Brasil a partir de 1961. Na época, tinha 34 anos, ao sair do Estado de origem percorreu cidades do Sudeste e Centro-Oeste, entretanto, foi no Rio de Janeiro que criou raízes bastante significativas, onde viveu mais de três décadas, sendo também o lugar em que morreu, no dia 15 de 
julho de 2004, poucos dias antes de completar 77 anos. Em paralelo à carreira de escritor desempenhou a de jornalista e a de advogado.

O autor teve uma infância curiosa que o direcionou para o universo da literatura. O fato de morar e de crescer no prédio do periódico Folha do Norte oportunizou um aprendizado único que definiu um eterno relacionamento com a escrita. Haroldo Maranhão amava escrever, era uma ocupação que sempre esteve presente na sua vida, como ele mesmo declarou: "Eu sou os meus textos; além deles, nada em mim ou de mim tem qualquer importância" (2002, p.7).

Ao longo de sua vida publicou diversas obras literárias, algumas delas com premiações memoráveis, todavia, cada uma de suas narrativas expressam identidades próprias de relatar acontecimentos da sociedade urbana, abrangendo diferentes temáticas, como a liberdade sexual, o psicológico do ser humano e o fantástico como em: A Estranha Xícara (1968); Vôo da Galinha (1980); A Morte de Haroldo Maranhão (Prêmio União Brasileira de Escritores/S. Paulo_1981); A Porta Mágica (Prêmio de Literatura Vértice/1983); O Tetraneto del Rei - O Torto: suas Idas e Venidas (Prêmio Guimarães Rosa/1980); Os Anões (Prêmio José Lins do Rego/1982); Jogos Infantis (1986); Rio de Raivas (1987); Cabelos no Coração (1990); Memorial do Fim (1991); Miguel, Miguel (1993), Querido Ivan (1998), etc.

O autor utiliza nos seus textos uma linguagem configurada na realidade social e cultural do indivíduo, fator que torna suas narrativas mais próximas do dia a dia do sujeito. Haroldo Maranhão teve sua escrita influenciada pelas obras de Machado de Assis, autor pelo qual possuía grande admiração e desejo em ressignificar 
a narrativa. A estima era tanta que o inspirou na produção do romance Memorial do Fim, um relato fictício que recriou a agonia e morte de Machado de Assis, uma forma de homenagear seu ídolo.

Mas eu escrevi e procurando, e perseguindo o ritmo do próprio Machado de Assis, que escrevia lentamente, né, até alcançar o tinteiro com a caneta, com aquela pena e tal. Mas eu posso dizer sim, agora, com segurança, que me deu mais satisfação, até porque me deu muito trabalho, foi este, o Memorial do Fim, a morte de Machado de Assis. (MARANHÃO, 2002, p.92)

Nas obras haroldianas, se percebe que os personagens possuem características psicológicas, devido aos pensamentos e às emoções serem semelhantes às de pessoas reais, que vão se modificando ao longo da narrativa, conforme o surgimento de novos acontecimentos. Isso causa diversas reações no leitor, tais como o medo, a curiosidade, o desejo, a hesitação, a surpresa, a loucura, etc. É como se, em um dado momento, a histórica ficasse mais intensa, fazendo o leitor experimentar as mesmas reações das personagens, por meio de uma descrição familiar e dialógica que permite a interação entre escritor, personagem e leitor.

De acordo com análise de Paulo Nunes (2002), "Haroldo Maranhão é escritor coringa", em virtude de ter habilidades de escrever obras em variados gêneros e para diferentes públicos, o acervo literário haroldiano envolve literatura infanto-juvenil, contos, memórias, romances, novelas, cartas e peça teatral. Apesar da genialidade do autor para com a prosa, ele não se considerava no começo de carreira, um bom escritor, via suas produções como "belíssimas porcarias", pois acreditava que o ofício de escritor era 
trabalhoso e doloroso, e só com prática e tempo, é que os textos melhoravam. Para Haroldo Maranhão, escrever é algo sério, como qualquer profissão, seja ela de bombeiro hidráulico, arquiteto, ou de engenheiro florestal, porquanto, o escritor acredita que:

Escrever dói, deixa a alma batida como um bife, deixa o corpo ofendido, rasga o peito e rasga o coração, e arrasta o operário desse ofício aos mais perigosos e últimos limites, além dos quais, um passo ou dois, já é loucura: o fim do gato já é o princípio do tigre, escrevi já não me lembro onde. Valerá a pena? (MARANHÃO, 2002, p.7)

Haroldo Maranhão era bastante crítico com os textos que escrevia, a ponto de publicá-los depois de 40 anos de idade, e, mesmo assim, pensar ter se precipitado. Ser escritor de ficção era um dos maiores desejos que tinha, um objetivo que buscou a sua vida toda e se empenhou muito em concretizar. Para realizar seu sonho, escrevia todos os dias; muitas vezes criava pequenas histórias e poemas, que depois foram organizados e publicados em livros.

A biografia de Haroldo Maranhão mostra que ele estava destinado a ser um excepcional escritor da literatura brasileira, uma das razões foi por nascer em um ambiente propício para fazer incríveis jornadas literárias. Desde a infância, tinha satisfação de ler e de escrever, um relacionamento que se tornou sério de modo que virasse profissão para vida inteira. Suas histórias curtas conquistaram e conquistam diversos públicos pelo Brasil por meio da linguagem singela, mas com qualidade de fazer o leitor questionar sua realidade entre a ironia e o humor.

Já Roger Elarrat é belenense, nascido em 1981. Possui no currículo a formação em Comunicação Social - Jornalismo pela Universidade 
Federal do Pará (UFPA). Atualmente, é professor no Instituto de Estudos Superiores da Amazônia (IESAM). No audiovisual, trabalha desde 2000. Começou a trabalhar, no audiovisual, como assistente de direção e diretor de $2^{\text {a }}$ unidade em curtas metragens paraenses. Dirigiu o curta-metragem Vernissage..." em 2006 e logo depois, o primeiro curta de animação em stop motion do Pará, Visagem!. É roteirista e diretor do documentário Chupa-Chupa: a história que veio do céu, projeto que ficou em primeiro lugar no DOCTVIII no estado do Pará. Dirigiu a adaptação para a televisão da obra Miguel Miguel de Haroldo Maranhão.

Miguel Miguel é a adaptação para TV da obra homônima do escritor Haroldo Maranhão. O telefilme foi apresentado na TV Cultura do Pará e na TV Brasil. Ele narra a história de um casal de aposentados que investiga a incrível história de Miguel, um amigo da família que, misteriosamente, morreu duas vezes. Cada momento traz uma nova descoberta, no antigo casarão de Úrsula e Varão, em uma trama que envolve o fantástico, o mistério e o humor negro.

\section{A OBRA: O DUPLO MIGUEL}

Tendo como base os pensamentos de Xavier (2003) que nos fala que, para iniciar qualquer processo de tradução, devemos começar observando o enredo, podemos dizer que o enredo da obra Miguel, Miguel de Haroldo Maranhão foi mantido em sua essência, na produção televisiva de Elarrat, pois o segundo no seu processo de tradução focou em momentos essenciais para a construção do realismo mágico presente na obra.

Realismo Mágico que segundo Chiampi: 
veio a ser um achado crítico-interpretativo, que cobria, de um golpe, a complexidade temática (que era realista de um outro modo) do novo romance e a necessidade de explicar a passagem da estética realista-naturalista para a nova visão ("mágica") da realidade. (2015, p.19)

Esse tipo de construção literária, que ficou muito associada aos escritores latino-americanos de língua espanhola, teve em Haroldo Maranhão um entusiasta, e essa relação entre o fantástico e o real que permeia toda a obra Miguel Miguel, que se mantêm no tom sombrio e nos fatos inexplicáveis presentes no filme.

A trama fantástica da narrativa ocorre pelo estranho hábito de Varão ler obituários. Desse estranho hábito, os dois processos narrativos (literário e televiso) puxam a temática da morte sob um olhar extranatural. Embora o assunto tenha um grau de severidade, percebemos em Haroldo Maranhão uma filosofia humorística para transgredir com a seriedade dos acontecimentos obscuros que são abordados de modo assombroso por muitos outros escritores, tom esse que permanece na narrativa fílmica.

A morte acaba por se transformar em tema central das narrativas, é ela que norteia o mundo das personagens. É vista em vários momentos como algo natural, que todos antes de passar para o outro plano, tinham uma vida normal, composta por família, emprego e amigos, assim como Miguel, um sujeito comum, semelhante a qualquer ser, um mero mortal que viveu e morreu, simples, sem muitos mistérios. Esse é um pensamento racional de encarar a morte, expressado por Varão.

O grande momento em que o insólito aparece, instaurando o fantástico na narrativa é a segunda morte do Miguel dos Arcanos 
Falbo Quillet, após 15 anos da cerimônia de seu primeiro enterro. A notícia sobre a segunda morte de Miguel quebra com o sentido natural da vida e da morte. O fato simplesmente aconteceu, provocando uma mudança drástica no cotidiano das personagens, especialmente do Varão, a figura central e narrador da história. Esses e outros acontecimentos estimulam em Varão ao longo da narrativa investigar diversas explicações racionais para o estranho fato.

Nas narrativas, percebe-se que há recursos da literatura fantástica moderna, em vista de haver elementos que provocam a incoerência nos eventos do cotidiano, a forma como a morte é abordada na obra expressa bem a falta de sentido que os procedimentos do fantástico promovem sobre os fatos conhecidos, demonstrando as fragilidades do sujeito diante de situações que fogem do controle da racionalidade.

Partindo desse rápido olhar sobre o enredo das duas narrativas, observaremos a relação de intermidialidade presente nos textos, focando três cenários importantes: a casa, o cemitério e o Nápoles; cenários presentes nas narrativas que causam essa aproximação das obras com o Fantástico.

\subsection{A CASA}

A casa de Varão é o lugar onde se passa a maior parte da história, e onde ocorrem diversos eventos inverossímeis. É nesse espaço que o protagonista se depara pela primeira vez com o evento sobrenatural, um fato que muda o cotidiano racional e o faz entrar em uma investigação maluca para descobrir se o amigo Miguel morreu de novo ou se tudo não passou de um grande engano. O vício de Varão de ler obituários acaba por levá-lo a uma 
situação estranha, como se a fixação do protagonista lhe pregasse uma peça cruel, revelasse a existência de um mundo paralelo, em que certos acontecimentos simplesmente se repetem sem a menor explicação, como a duplicação da morte do amigo, sob as mesmas circunstâncias, revivendo por mais um dia, o enterro de Miguel, no mesmo cemitério e horário, mas com uma diferença de tempo, quinze anos após o primeiro sepultamento.

Os acontecimentos insólitos demonstram que a compulsão em ler as páginas dos obituários provocou problemas na vida de Varão, tanto no meio social quanto no campo psicológico, devido ter ele dificuldades em perceber o que é real ou não, de diferenciar acontecimentos da imaginação com os da realidade. Em vários momentos do filme, são marcados esses devaneios, tanto que seu diretor quis marcar esse traço da personalidade de Varão logo na primeira cena da obra, quando estão todos reunidos à mesa para um jantar de domingo.

Já na narrativa literária, temos a preferência por deixar subentendida essa loucura de Varão, normalmente colocada na obra através das suas várias teorias sem sentido que, ao mesmo tempo em que dão um ar de comédia ao livro, também revelam que Varão não possui tanta clareza do que está falando e pensando. Essa incoerência de fatos faz o narrador-personagem das obras viver em muitos conflitos com as demais personas de Miguel Miguel, uma delas é a esposa Úrsula, a qual é a pessoa que Varão mais dialoga na história.

Úrsula aparece em dois momentos nas tramas. O primeiro demonstra ser um sujeito frágil, que se abala com facilidade diante de eventos que fogem da racionalidade, de maneira que Haroldo 
Maranhão caracteriza a personalidade da personagem como: “(...) senhora de almazinha sensível, vulnerável" (p.20), descrição mencionada em várias situações pelo narrador, a qual se confirma na atitude da mulher em recusar de ir ao segundo enterro de Miguel. Apesar de também ser frágil, a Úrsula de Ellarat aparenta ser mais resignada desde o início, aceitando a condição de Limbo em que estão, em que a casa se encontra, onde tudo é duplo.

Úrsula só aparece interagindo com Varão na casa, ou seja, ela não o segue na jornada afora acerca do acontecimento anormal e nem aparece interagindo com os outros personagens, apenas com Varão, uma ação estranha uma vez que os dois são os únicos personagens que têm a percepção inicial de que há algo de errado com a informação do obituário, além de sentirem perturbações nas suas rotinas. Varão, mesmo surpreso com a notícia mantém a calma e tem a certeza de uma coisa, que só se morre uma vez, conforme a citação abaixo:

Não. Não houve nada. Quero dizer: não se morre duas vezes. Ninguém morre duas vezes. Morre-se uma vez. Todo mundo morre uma vez. E pronto, acabou-se. Nós vimos os miguéis naquela tarde. Morreu naquele dia. Morreu ou não morreu? [...] (MARANHÃO, 1993, p.24-25)

No segundo momento em que Varão se encontra com a esposa para provar, por meio de fotografias, que realmente houve um segundo enterro de Miguel, ocorre mais um fato incomum, o comportamento de Úrsula se altera, indicando uma incoerência na personalidade da personagem que antes fora descrita pelo narrador como ser sensível e vulnerável, pois a esposa de Varão não transmite fraqueza emocional ao ver as fotos do funeral e nem se abala ao 
reconhecer nas imagens a amiga Miguela. Não sente medo e nem receio ao analisar as fotografias do Miguel no caixão, uma evidência de que o enterro era mesmo de Miguel. Essa aceitação e mudança por parte de Úrsula na obra literária são marcadas pelas fotos. Já no filme, o diretor utiliza um recurso mixmidia, pois a transformação de Úrsula parece ocorrer após ela voltar a tocar piano, coisa que ela não fazia há muito tempo.

A passagem do tempo e também da entrada em um plano tempo sobrenatural e é marcada pelo diretor por meio do cenário: a casa que antes da morte de Miguel era velha, porém muito bem cuidada, acaba por se transformar em uma casa deteriorada, mal cuidada, cheia de mofo, dando a impressão de ser um local sombrio, onde o diretor consegue trabalhar a transposição midiática, do trabalho com o fantástico, aparecendo, não apenas na temática da morte, como também no cenário, nas músicas, em vários elementos dessa nova mídia para que a obra foi traduzida.

O jogo da duplicação da morte de Miguel é o principal elemento causador do fantástico na narrativa, em virtude de modificar a rotina de Varão, de modo que os eventos seguintes sejam regidos sob coisas irreais, a partir do conhecimento que comandam os demais eventos incoerentes. O narrador-personagem entra em um mundo governado pelo impossível, em que presencia mais de um evento extranatural. Segundo Ceserani (2006), as duplicações de fatos ou personagens na narrativa são procedimentos fantásticos que representam a loucura, o transtorno psicológico em compreender certas ações ou a passagem de tempo. Dessa forma, o teórico do modo fantástico defende que: 
O procedimento narrativo das transformações ou metamorfoses interiores e exteriores dos personagens; o contínuo jogo de espelhos entre aparência e realidade e o constante debate sobre a identidade dos personagens; a série significativa de atos falhos, distúrbios psicológicos, de percepções fantásticas do tempo, do espaço, da relação entre o claro e o escuro; a presença do diabo, seja sob trajes burgueses seja sob trajes declaradamente e pitorescamente diabólicos; elaboração refinada dos temas relativos ao duplo (personagens que se refletem em outros personagens, personagens que se duplicam tendo nomes diferentes, personagens que se transformam na própria sombra, ou na própria imagem). (CESERANI, 2006, p.29-30)

Considerando a teoria ceseraniana, se compreende que Varão está passando por algum transtorno de percepção dos acontecimentos, o qual confunde a realidade com a imaginação, parece que todos os fatos são invenções do narrador, e nem ele consegue distinguir o que é verdade e o que é falso nas situações relatadas. Além da casa, há mais fatos insólitos que provam ainda mais a loucura de Varão, que serão analisados.

\subsection{O CEMITÉRIO}

O cemitério é o grande local em que se instaura o fantástico no telefilme, enquanto no livro é a casa. No filme, Elarrat decide colocar um elemento místico para inserir o fantástico, a água. Ainda no cemitério, Varão e Úrsula veem o tempo "fechar", as nuvens escurecerem e o vento forte bater, tanto que as portas da capela se abrem para eles, instaurando nesse momento o fantástico. Depois disso, a chuva cai e parece mudar tudo na vida dos dois, tanto que a chuva no filme parece durar 15 anos. 
Já no livro não temos esses elementos, porém outro momento presente nas duas obras chama a atenção, a ida de Varão ao segundo enterro de Miguel no Cemitério de São Francisco Xavier. Isso simboliza um dos momentos de maiores conflitos durante a jornada do protagonista em descobrir a verdade, se o amigo morreu de novo ou não. Ao chegar ao recinto, passou por algumas experiências iguais às de quinze anos atrás, uma delas fora no instante que ele entrou na segunda capela e leu no quadro de aviso o nome da pessoa que seria sepultada naquele dia e, para sua surpresa, viu escrito com letras maiúsculas: MIGUEL DOS ARCANOS FALBO QUILLET. No filme apenas se lê MIGUEL DOS ARCANOS.

A partir dessa evidência, Varão evita de olhar os rostos das pessoas presentes no funeral, com o intuito de controlar as próprias emoções. A atitude do personagem de baixar a visão representa um certo temor e insegurança de enfrentar a realidade que vive no ambiente. Apesar de sempre negar e expressar com convicção de que não é possível um ser morrer duas vezes, sente um grande desconforto ao ver, novamente, o nome completo de Miguel como sendo o morto que será sepultado.

Nesse breve momento, Varão passa pela primeira vez por uma inquietação, em vista de não ter certeza do que realmente está acontecendo, pois o que presenciou está fora do campo do conhecido. Essas sensações são peculiares nas narrativas fantásticas, principalmente nas obras contemporâneas, que exploram as angústias do indivíduo diante da falta de controle de certas situações que, de acordo com Ceserani (2006, p.12), “(...) o modo fantástico é usado para organizar a estrutura fundamental 
de representação e para transmitir de maneira forte e original experiências inquietantes a mente do leitor".

Todavia, é no encontro com Miguela (esposa de Miguel) que o senhor dos obituários perde o controle da situação, a ponto de provocar uma confusão no enterro, quando vê o rosto de Miguela e não a reconhece. O estranho se instaura na situação quando minutos antes de levantar os olhos e olhar para a face da viúva a havia abraçado e ela tinha falado no nome da Úrsula.

Varão encara Miguela e percebe que a mulher era uma estranha, de acordo com a narrativa de Haroldo Maranhão (1993, p.30) "Estremeci sem que notassem: jamais havia visto semelhante mulher, jamais: uma estranha". Ficou tão surpreso e indignado que causou um tumulto para obter uma explicação. Seguindo os estudos de Ceserani (2006), se compreende que na obra, o sujeito tem dificuldades de encarar a realidade em que o eu, a consciência não consegue reconhecer determinados eventos ao redor por algum problema psicológico. Neste caso, a teoria do modo fantástico ajuda a desvendar os acontecimentos e as ações dos personagens, no caso de Varão, olhando sob a perspectiva do fantástico se entende que o narradorpersonagem não consegue recordar ou explicar determinados acontecimentos. Parece que passa por algum transtorno psicológico de modo que não tem controle de certas atitudes no meio externo. Sua loucura parece se agravar por não saber diferenciar o real da imaginação, passando por conflitos no campo externo.

\subsection{O NÁPOLES}

A maior loucura de todas se dá quando Varão vê o Miguel vivo, um dia depois do segundo enterro e mesmo assim tenta esclarecer 
se sua morte é verídica ou não, e se assim for, quando realmente aconteceu? Há 15 anos, ou foi no dia anterior? De acordo com os questionamentos do protagonista, a seguir:

Morreste, Miguel. Só quero saber quando. Ontem? Ou há quinze anos atrás? E por que diabo me pareces agora no Nápoles? O obituário publicou ontem o teu nome: pela segunda vez em quinze anos. Eu sou calmo, calmíssimo, tu sabes. Mas a Úrsula está à beira da loucura. Como um irmão, Miguel. Um amigo falando a outro amigo. Eu te peço. (MARANHÃO, 1993, p.43)

Uma pessoa equilibrada não se atreveria a conversar ou a tirar dúvidas com um ser que já morreu. A palavra loucura é citada em vários momentos das duas narrativas. Dessa forma, subentende que Varão estava louco e imaginou a segunda morte do amigo. No entanto, Haroldo Maranhão deixa no ar, mantém até a última página se Miguel morreu ou não, fazendo o personagem principal hesitar sobre a morte do amigo. Esse elemento demonstra que o efeito fantástico permanece até o fim da narrativa. De acordo com a teoria todoroviana:

Existe uma outra variedade do fantástico em que a hesitação se situa entre o real e o imaginário. No primeiro caso, duvida-se não de que os acontecimentos tivessem sucedido, mas de que nossa compreensão tivesse sido exata. No segundo, pergunta-se se o que acreditamos perceber não é de fato fruto da imaginação. (TODOROV, 2014, p.42)

O filme consegue manter mais ainda este estado de tensão e de hesitação, pois, após a conversa no Nápoles, ele nos levanta a suspeita se Miguel realmente morreu alguma vez se quer, pois, ao 
final do filme, Miguel e Miguela aparecem novamente almoçando macarronada no Domingo, com Varão e Úrsula. Será que Miguel realmente morreu? Ou será esse momento mais uma criação da cabeça de Varão? As dúvidas são muitas e elas também são elementos de produção do fantástico em uma obra.

\section{CENAS FINAIS: CONSIDERAÇÕES}

Podemos observar que a possibilidade de se traduzir uma obra entre mídias é algo possível, sem que necessariamente o cerne da obra seja perdido. A obra Miguel Miguel, de Haroldo Maranhão, possui uma característica de literatura Fantástica, se aproximando bastante do realismo mágico; e Elarrat, quando traduziu esse texto para o cinema, manteve essa essência, mudando e acrescentando novos elementos que essa nova mídia permitia trazer.

A Obra de Maranhão possui uma tendência mais universal. Apesar de se passar no Rio de Janeiro, essa tendência fica bem clara quando Elarrat transpõe essa narrativa para Belém, onde os mesmos fatos acontecem.

Por fim, de acordo com os estudos do fantástico se percebe, nas duas narrativas de Miguel Miguel, muitos elementos da literatura fantástica e do cinema de terror e da ficção cientifica, que fazem o leitor/expectador se envolver em uma jornada improvável para desvendar a verdade sobre o segundo enterro de Miguel. Dentre os aspectos do fantástico se percebem na obra: a hesitação, o conflito, a mudança de comportamento, o medo, a loucura, entre outras características. 


\section{REFERÊNCIAS}

CESERANI, Remo (2006). O Fantástico. Nilton Tripadalli (Trad.). Curitiba: Ed. UFPR. Chiampi, I. (2015). O realismo maravilhoso. São Paulo: Ed. Perspectiva. Clüver, Claus (2011). Intermidialidade. Pós: Revista do Programa de Pósgraduação em Artes da Escola de Belas Artes, Belo Horizonte. 1(2), 8-23, nov.

(2006). "Inter textus/ Inter artes/ Inter media". Elcio Loureiro Cornelsen (Trad.). Aletria: Revista de estudos de literatura, Belo Horizonte: CEL, FALE, Universidade Federal de Minas Gerais, 14, jul.-dez.

JOHNSON, Randal (1987). Literatura e cinema. Macunaíma: do modernismo na literatura ao cinema novo. São Paulo: T. A. Queiroz.

MARANHÃO, Haroldo (2002). "A leitores e a possíveis leitores" In: Asas da Palavra. Belém: Unama, 6(13),7-9. Jun.

(1993). Miguel Miguel. Belém: Edições CEJUP.

MOSER, Walter (2006). "As relações entre as artes. Por uma arqueologia da intermidialidade". Eliana Lourenço de Lima (Trad.). Aletria. Revista de estudos de literatura. Belo Horizonte: CEL, FALE, Universidade Federal de Minas Gerais, 14, 42-65, jul-dez.

MÜLLER, Adalberto Jr. (2008). "Além da literatura, aquém do cinema? Considerações sobre a intermidialidade". Revista de Pós-graduação em Literatura Outra Travessia. Florianópolis: Universidade Federal de Santa Catarina, 7, 47-53.

PLAZA, Júlio (2003). Tradução Intersemiótica. São Paulo: Perspectiva.

RANCIÈRE, Jacques (2012). O Espectador emancipado. São Paulo: WMF Martins Fontes.

SCHOLLHAMMER, Karl Erik (2009). Ficção Brasileira Contemporânea. Rio de Janeiro: Civilização Brasileira.

TAVARES, Mirian (2006). Cinema e Literatura: desencontros formais. Intermídias n. 5-6, ano 2. In http://ebookshopbrasil.com. $\mathrm{br} / \mathrm{siteebookshop/phocadownloadpap/gratuitosver/cinema}$ cinemaeliteraturadesencontrosformais_miriantav.pdf. Acesso em: 10.Jul.2017. 
VENEROSO, Maria do Carmo de Freitas (2006). "A letra como imagem, a imagem da letra". In: NAZARIO, Luiz (Org). Concepções contemporâneas da arte. Belo Horizonte: Editora UFMG.

XAVIER, Ismail (2003). "Do texto ao filme: a trama, a cena e a construção do olhar no cinema". In: PELLEGRINI, Tânia. et al. Literatura, Cinema e Televisão. São Paulo: Editora Senac São Paulo: Instituto Cultural.

NUNES, Paulo (2002). "Viagem de amor a um país chamado Belém”. In: Asas da Palavra -revista da graduação em Letras. Belém: Unama, 6(13), 15-17. Jun.

TODOROV, Tzvetan (2014). Introdução à Literatura Fantástica. São Paulo: Perspectiva. 